\title{
Evaluation of structural damage of the spine, sacroiliacs and the hip in Tunisian Spondyloarthrities patients with hip involvement
}

\author{
Maatalah K 1, Essafi F1, Mahmoud I 2, Hamdi W 1, Ben Abdelghani K 3,kchir MM 1, \\ Tekaya R2, Abdelmoula L2 \\ 1-Department of Rheumatology, Institute Orthopedic Mohamed Kassab \\ 2-Department of Rheumatology, Charles Nicolle hospital \\ 3-Department of Rheumatology, Monji Slim hospital
}

Introduction: Coxitis is a spondyloarthritis( SpA) serious complication. Indeed, its outcome on young and active ground alters both functional prognosis and life quality.

The objective of this study was to evaluate structural damage of the spine, sacroiliacs, and the hip, Tunisian Spondyloarthrities patients with hip involvement

Methods: This is a transversal study, including SpA patients (satisfying ASAS criteria 2009) with hip involvement. Demographic and clinical data were collected and analyzed. Structural sacroiliacs and hip evaluation was made using X-ray of the pelvis and BASRI hip. Radiographic forms of hip disease were evaluated. Sacroiliac involvement was assessed using the Forestier classification. The structural damage of the spine was evaluated on face and profile radiographs of the cervical and lumbar spine. Two scores have been used: BASRI score (Bath Ankylosing Spondylitis Radiologic Index), and mSASSS (modified stoke Ankylosing Spine Score).

\section{Results:}

\begin{tabular}{|l|l|}
\hline Patients & $\mathbf{9 4}$ \\
\hline Sexe-ratio & 0,81 \\
\hline Mean age (years) & $41,53 \pm 11,97$ \\
\hline $\begin{array}{l}\text { Median age at disease onset } \\
\text { (years) }\end{array}$ & $26,23 \pm 10,29$ \\
\hline Mean diagnostic delay (years) & 6,48 \\
\hline Median BASDAI & 5,4 \\
\hline Median BASFI & 5,5 \\
\hline
\end{tabular}

peripheral joint involvement was found in 33\% of cases. Extraarticular manifestation was seen in $57 \%$ of patients

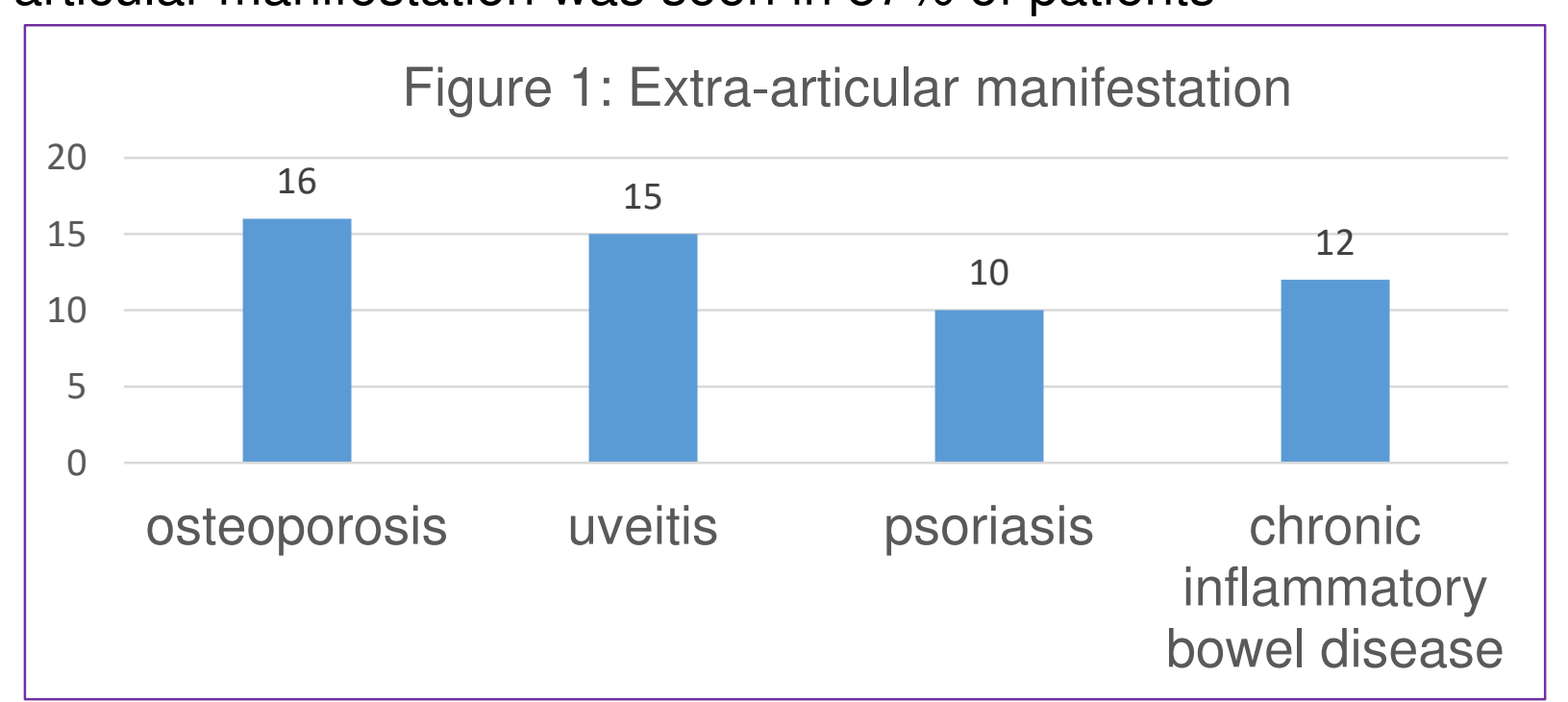

- Sacroiliitis grade was 2 in $17 \%, 3$ in $37 \%$ and 4 in $46 \%$ of cases. 147 hips were evaluated

- 78 patients had bilateral hip involvement. 147 hips were evaluated.

- Mean BASRI-hip score was 2,07.

\begin{tabular}{|r|r|}
\hline m SASSS & score \\
\hline Cervical spine & 7,51 \\
\hline Lumbar spine & 8,73 \\
\hline total & 15,34 \\
\hline
\end{tabular}

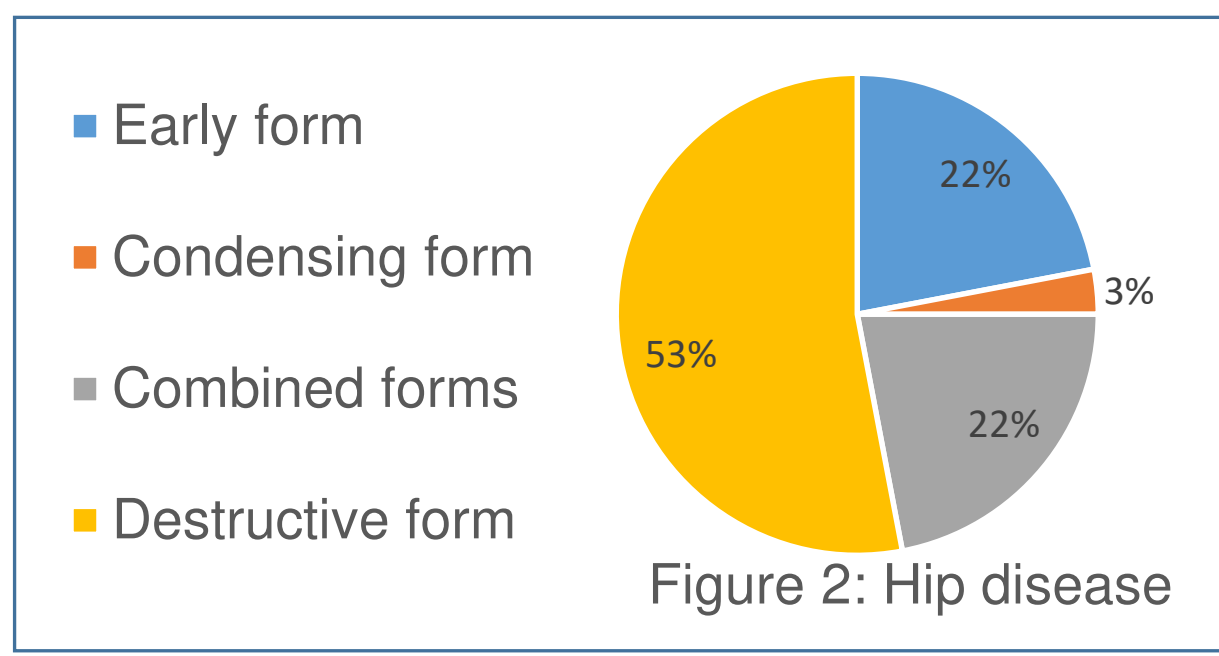

Discussion : BASRI,SASSS, and m-SASSS were developed that were tested for reliability in quantifying structural damage [1-2]. BASRI includes cervical and lumbar spine as well as sacroiliac joints. Similar scoring is available also for hips. These scoring methods are those that are mostly used in clinical and observational studies [3]. SASSS is a scoring system that evaluates only cervical spine, whereas M-SASSS evaluates both lumbar and cervical spines. In a 4-year follow-up study on 217 patients with AS, Wanders et al. [4] investigated which method is the most appropriate in evaluating progression. For that purpose, they performed radiographic evaluation using BASRI, SASSS, and MSASSS on radiographs taken at year $0,1,2,3$, and 4 . According to the result of this study, they concluded that M-SASSS was the best radiological method in determining progression

Conclusion: Our findings confirm tunisian observations that studied Spa with hip involvement. This population had a particularly severe structural damage of the spine.

[1] Calin A, Mackay K, Santos H, Brophy SA (1999) New dimension to outcome: application of the Bath ankylosing spondylitis radiology index. J Rheumatol 26:988-992

[2] Creemers MC, Franssen MJ, van't Hof MA, Gribnau FW, van de Putte LB, van Riel PL (2005) Assessment of outcome in ankylosing spondylitis: an extended radiographic scoring system. Ann Rheum Dis 64:127-129

[3] Van der U“" nden (1997) Ankylosing spondylitis. In: Kelley WN, Haris ED, Ruddy S, Sledge CB (eds) Texbook of rheumatology. Saunders Company, W. B. Philadelphia, pp 969-982

[4] Wanders AJ, Landewe RB, Spoorenberg A, Dougados M, van der Linden S, Mielants H, van der Tempel H, van der Heijde DM (2004) What is the most appropriate radiologic scoring method for ankylosing spondylitis? A comparison of the available methods based on the Outcome Measures in Rheumatology Clinical Trials filter. Arthritis Rheum 50(8):2622-2632 